\title{
A survey of Denplan patients in the North West Region
}

\author{
A geodemographic analysis of the Denplan patient population in the North West Region by M. Tickle, A. S. Blinkhorn, \\ P. J. B. Brown, and R. Matthews Br Dent J 2000; 189:494-499
}

\section{Objective}

To provide a preliminary descriptive investigation of Denplan patients in the North West Region, by plotting the age/gender and payment banding distribution, and to identify the area types where Denplan patients live and the areas in the North West Region where Denplan practices are most likely to thrive.

\section{Setting}

North West Region of England

\section{Subjects and Materials}

The study included Denplan patients resident in the North West Region. Age/gender and payment banding frequency distributions were constructed. A market penetration ranking report using the Target Market level of the Super Profiles geodemographic classification was produced by a spreadsheet analysis in Microsoft Excel. A Lorenz curve was plotted to graphically represent the output of the market penetration analysis. Following the market penetration analysis the enumeration districts (EDs) of the six top ranked Target Markets in the North West Region were identified and mapped out across the Region. Finally, the number and percentage of EDs in the six top ranked Target Markets were identified for each health authority in the Region.

\section{Results}

47,106 patients were registered with Denplan. In all but one 5year age band (16-20-year-olds) female patients were in the majority. Patients were concentrated $(40.5 \%)$ into the $40-55$ age group. Nearly $50 \%(22,329)$ of patients were allocated to the second lowest payment banding. Under $0.5 \%$ of patients $(N=199)$ were categorised into the highest payment band. The Target Markets at the top of the penetration ranking were more affluent in nature, with a strong rural element and an older demographic profile as part of their descriptive titles. At the bottom of the ranking deprived area types with young demographic profiles predominated. About one half (49.9\%) of Denplan patients were present in just over a quarter $(25.7 \%)$ of the total population of the North West Region. The Lorenz curve demonstrated that Super Profiles at Target Market level had an effectiveness of $37.9 \%$ in segmenting the population of the North West Region according to Denplan registration status.

\section{Conclusions}

The population using this service in the North West Region tend to be from more mature, rural and affluent.

\footnotetext{
In Brief

- Geodemographic classifications and GIS are commonly used by business to target the sales of products and services. These methodologies are applicable to the marketing of dental services, particularly in the independent sector.

- The population registered with Denplan in the North West Region tended to be from more mature, rural and very affluent area types.

- About half of Denplan patients In the North West Region could be found in a quarter of the total population of the Region.

- This methodology can demonstrate a clear association between uptake of primary dental care under the Denplan brand name and the characteristics of populations living in certain area types.

- The reasons for the associations are probably complex and would require further investigation to understand why patients seek care in the independent sector.
}

\section{Comment}

Since the introduction of NHS General SDental Services in 1948 there have been a large number of changes in the NHS contract with general dental practitioners which may have influenced patients to seek treatment and dentists to provide it under a private fee per item, capitation or insurance basis. Denplan is a private capitation-based scheme which was founded in 1986 and by the end of 1987 had 8,000 registered patients. By April 2000 this number has increased to 914,000 patients registered with 5,500 dentists.

This study set out to investigate the distribution of Denplan patients in the North West of England and to plot the age/gender and payment banding distribution. Of the 6.3 million population in the North West Region, $61 \%$ were registered with the NHS and only $0.07 \%$ with Denplan. The majority of the Denplan patients (59\%) were female and $41 \%$ of all patients were in the $41-55-$ year-old age group. Only 34 patients of the 47,000 registered in the North West were below 6 years of age. Nearly $50 \%$ of patients were allocated to band B, a comparatively low risk category in the payment banding structure, suggesting a preventive behaviour pattern consistent with more affluent sectors of the population. Postcodes were used to identify the enumeration district (ED) in which patients lived, these being population groupings of about 400 individuals. This process also added the Super Profiles values for each ED, and the 40-group Target Market level of the classification was used to segment the population.

This process, commonly used by large retailers, was used to analyse the market penetration of Denplan in different sectors of the community. It was found that the
Target Markets at the top of the ranking were more affluent, had an older demographic profile and had a strong rural element. At the bottom of the ranking were areas of deprivation, high unemployment and a younger demographic profile.

Further research needs to be undertaken to investigate the influences on the uptake of dental care in the independent sector particularly the extent to which patients will travel to access their dental care. In addition, the selection of practices by patients may be subject to different variables, such as the qualities of the individual dentist or dental team, in comparison with their selection of retailers such as supermarkets.

\section{R S Ireland}

Professor Primary Dental Care, University of Liverpool 